\title{
Familial steroid-resistant nephrotic syndrome with sensorineural deafness
}

INSERM

\section{Source}

INSERM. (1999). Orphanet: an online rare disease and orphan drug data base. Familial steroid-resistant nephrotic syndrome with sensorineural deafness. ORPHA:280406

Familial steroid-resistant nephrotic syndrome with sensorineural deafness is a rare, genetic coenzyme Q10 deficiency characterized by sensorineural deafness and severe, progressive nephrotic syndrome not responding to steroid treatment. Clinical manifestations include early onset proteinuria, hypoalbuminemia and edema, leading to end-stage renal disease. The renal biopsy reveals focal seg mental glomerulosclerosis and diffuse mesangial sclerosis. Rarely, seizures, ataxia and dysmorphic features have been described. 